\title{
Analysis on Diagnosis of Family Clustering Infection of SARS-CoV-2
}

Rong Qiu

Sichuan University West China Hospital

Ming-wei Liu

Kunming Medical University First Affilliated Hospital

Chuan Zhao

Suining Central Hospital

Wei-min Li ( $\square$ weimi003@126.com )

Sichuan University West China Hospital https://orcid.org/0000-0003-0826-0635

Research article

Keywords: novel coronavirus, diagnosis, family clustering

Posted Date: April 6th, 2020

DOI: https://doi.org/10.21203/rs.3.rs-21188/v1

License: (c) (i) This work is licensed under a Creative Commons Attribution 4.0 International License.

Read Full License 


\section{Abstract}

Background: Novel coronavirus (nCoV, SARS-CoV-2) infection has complicated and diversified symptoms, but no special treatment. In this study, diagnosis and treatment of family clustering nCoV infection were analyzed.

Methods: The Sichuan Suining Central Hospital received 11 patients with confirmed nCoV virus infection from 4 families during January 23rd, 2020 to February 20th, 2020. Their clinical symptoms, treatment conditions and changes of disease state were reviewed in the present study.

Results: In all 4 families, there were 1-2 members in each family who had contact with epidemic disease. Clinical manifestations were: 3 cases had debilitation only, 1 case had cough only, 1 case had diarrhea, 5 cases had fever and cough, and 1 case had blood-stained sputum. According to image changes, no image change was observed in 1 child patient. Multiple focal ground-glass opacities were detected from 2 patients and multiple patchy shadows were observed from 8 patients, especially in lung periphery. Complications: there were hypertension in 3 cases, diabetes in 2 cases, depression in 1 cases and hypertension and diabetes in 1 case. Moreover, there's one patient who had rheumatic heart disease and received mitral and aortic valve replacement 2 years ago. All 11 cases divided into mild type (1 child patient), moderate type (8 patients), severe type (1 patient) and critical type (1 patient). Treatment: 11 patients were treated with intravenous drip of ribavirin injection (adult $0.5 \mathrm{~g} / \mathrm{time}$; child $15 \mathrm{mg} / \mathrm{kg}$.time,twice per day) and lopinavir/ritonavior (adult: 2 tablets/ time; child: 1/2 tablets/times, twice per day) for 6-12 days, accompanied with appropriate amount of intravenous drip of antibiotics. Discharge: After treatment, 11 patients met the discharge criteria and were allowed to discharge. Adverse reactions: 4 patients had loose stools and abdominal discomfort, and another 2 cases had diarrhea.

Conclusions: SARS-CoV-2 infection have complicated and diversified symptoms, which shall be identified according to epidemic history and novel coronavirus nucleic acid test. In particular, the whole family in which there's a patient with confirmed SARS-CoV-2 shall be isolated for screening in addition to the patient. The lopinavir/ritonavior administration combined with ribavirin or recombinant Human Interferon $(\mathrm{RHI}) \mathrm{a} 2 \mathrm{~b}$ is effective, accompanied with mild adverse reaction.

\section{Background}

Pneumonia cases with unknown causes occurred continuously in Wuhan City, Hubei Province since December, 2019. Subsequently, such pneumonia spread quickly to the whole Hubei Province, the whole China and many countries and regions in the world. According to complete genome sequencing, such pneumonia was proved as the consequence of a novel coronavirus (nCoV) infection (SARS-CoV-2) [1]. The Word Health Organization (WHO) reported that more than 43,000 confirmed cases of nCoV infection have been identified in 28 countries and regions, in which more than 99\% were in China [1]. WHO announced COVID-19 as the sixth public health emergency which was concerned around the world on January $30 \mathrm{~h}$, 2020. SARS-CoV-2 is closely related with two severe acute respiratory syndrome coronaviruses (bat-SLCoVZC45 and bat-SL-CoVZXC21) which were derived from bat [2]. It spread through spraying or direct 
contact of people. It is estimated that the average incubation period of infection is 6.4 days and the basic number of reproduction is 2.24-3.58. In patients with pneumonia caused by SARS-CoV-2 (novel coronavirus pneumonia or Wuhan pneumonia), fever is the most common symptom, followed by cough. It found from chest computed tomography (CT) images that the most common symptom was to groundglass opacities (GGO) at two sides of lungs. At present, some study pointed out that some patients have non-typical symptoms, including debilitation only, diarrhea only and some even showed no symptoms. These patients were very easy to be missed in diagnosis, thus causing delayed treatment and spreading of the disease. Particularly, the whole family in which there's a patient with confirmed SARS-CoV-2 shall be isolated for screening in addition to the patient. There's no specific medicine for SARS-CoV-2 and some patients have progressed to severe novel coronavirus pneumonia with poor prognosis and high death rate. Early diagnosis and intervention not only can cure patients as early as possible and protect them from development to novel coronavirus pneumonia, but also can prevent diffusion of the disease. No specific medicine is available yet for SARS-CoV-2. However, this study discovered certain clinical effect of ribavirin injection combined with lopinavir/ritonavior for 11 patients with SARS-CoV-2 from 4 families who were hospitalized during January 23rd, 2020 to February 20th, 2020.

\section{Methods}

\section{General information}

A total of 11 patients with SARS-CoV-2 from 4 families who were received in Sichuan Suining Central Hospital during January $23^{\text {rd }}, 2020$ to February $20^{\text {th }}, 2020$ were collected as research objects. They were divided into mild type (1 case), moderate type (8 cases), severe type (1 case) and critical type (1 case). These 11 patients were composed of 6 males and 5 females aging from 4-71. They showed significant family clustering infection. Among them, there were 3 asymptomatic patients.

\section{The latest diagnosis standard and clinical classification of SARS-CoV-2, disisolation and discharge standards, follow- up visits}

Diagnosis standards: chest CT of COVID-19 showed some characteristics. The Diagnosis and Treatment Program for Pneumonia Caused by Novel Coronavirus Infection ( $5^{\text {th }}$ trial version) has viewed pneumonia imaging features of suspicious cases in Hubei Province as an independent standards for clinical diagnosis of COVID-19. Chest CT images: there are multiple patchy shadows and interstitial changes in early stage, especially in lung periphery. These will further progress to multiple GGO and infiltration shadows at two sides of lungs, and even may cause lung consolidation. Pleural effusion is rare. Testing novel coronavirus nucleic acid of nasopharynx swab, phlegm, lower respiratory secreta, blood and faeces based on the real-time polymerase chain reaction (PCR) is the gold standard for diagnosis of COVID-19 [3]. According to laboratory examination, total number of peripheral blood leucocyte in early stage of 
COVID-19 is normal or decreased, while the lymphocyte count decreases. Some patients had increases of liver enzyme, creatase and myohemoglobin. Most patients presented increases of C-reactive protein (CRP) and erythrocyte sedimentation rate (ESR), but normal procalcitonin (PCT). Severe patients had increase of D-dimer and progressive reduction of peripheral blood lymphocyte

Clinical classification: 1) mild type: mild clinical symptoms and no pneumonia manifestation on images. 2) Moderate type: fever and respiratory symptom, accompanied with pneumonia manifestation on images. Moderate type has high risks to be developed to severe type upon any one of following conditions: 1. continuous hyperpyrexia; 2 . Old; 3. Serious basic diseases; 4. Quick progresses in two successive lung CT examinations. 3) Severe type: patients conforming to any one of following items are evaluated as the severe type: 1 . Respiratory distress, RR $>30$ times /min; 2 . Oxygen saturation $<93 \%$ under quiescent condition; 3. Arterial partial pressure of oxygen $\left(\mathrm{PaO}_{2}\right)$ / oxygen uptake $\left(\mathrm{FiO}_{2}\right)<=300 \mathrm{mmHg}$. 4) Critical type: patients conforming to any one of following items are evaluated as the critical type: 1 . Occurrence of respiratory failure and requiring mechanical ventilation; 2) occurrence of shock, combined with other organ failure and ICU monitoring treatment [4].

Clinical manifestations: fever, debilitation and dry cough are main manifestations. There are rare upper respiratory symptoms, such as nasal obstruction and rhinorrhea. About half percentage of patients had breathing difficulties after one week and severe patients might be developed to acute respiratory distress syndrome, septic shock, and irreformable metabolic acidosis and coagulation disorders. It is important to note that severe and critical patients might suffer middle-grade and low-grade fever, and even no evident fever in the course. Some patients have mild onset symptoms and no fever, and they were recovered after one week. Most patients had good prognosis and few patients suffered severe symptoms and even died.

Disisolation and discharge standards: body temperature recovered for at least 3 days, significant improvement of respiratory symptoms, great improvement of acute exudative lesion in lung images, and negative test of two successive respiratory pathogenic nucleic acid tests (sampling interval was at least 1 day). Diagnosis and Treatment Program for Pneumonia Caused by Novel Coronavirus Infection ( $6^{\text {th }}$ trial version)

Follow-up visit: Self-health monitoring lasted for 14 days after discharge. All patients were asked not to go for outdoor activities and return to hospital for follow-up visit and return visit at the second and fourth weeks after discharge. Diagnosis and Treatment Program for Pneumonia Caused by Novel Coronavirus Infection (6 $6^{\text {th }}$ trial version)

\section{Treatment method}

The mild child patient (4 years old) was administrated with $2.75 \mathrm{ml}$ lopinavir / ritonavir oral liquid (twice per day) and intravenous drip of $0.17 \mathrm{~g}$ ribavirin injection ( $1 \mathrm{ml}: 0.1 \mathrm{~g} * 10 \mathrm{pcs} /$ box) every $12 \mathrm{~h}$ for one week. Meanwhile, the child was asked to take azithromycin orally. 
7 moderate patients were treated with intravenous drip of $0.5 \mathrm{~g}$ ribavirin injection $(1 \mathrm{ml}: 0.1 \mathrm{~g} \star 10 \mathrm{pcs} / \mathrm{box})$ every $12 \mathrm{~h}$ (twice per day) and two pieces of lopinavir/ritonavior (twice per day) for 7-10 days. In the same time, patients were given with reasonable amount of antibiotics by oral or intravenous drip.

1 severe patient and 1 critical patent were treated with 5,000,000 U RHI a2b injection (3,000,000 U/pc) and aerosol inhalation of $2 \mathrm{ml}$ sterile water for injection ( $5 \mathrm{ml} * 50 \mathrm{pcs} /$ box), twice per day. Besides, they took 2 pieces of lopinavir/ritonavior, twice per day. The whole treatment program lasted for 6-12 days, accompanied with appropriate amount of intravenous drip of antibiotics. The critical patient was also provided with mechanical ventilation. During the treatment, severe and critical patients were treated by resochin for 4-5 days for evident respiratory symptoms.

1 moderate patients were treated with intravenous drip of $0.5 \mathrm{~g}$ ribavirin injection $(1 \mathrm{ml}: 0.1 \mathrm{~g} \star 10 \mathrm{pcs} / \mathrm{box})$ every $12 \mathrm{~h}$ (twice per day) and two pieces of lopinavir/ritonavior (twice per day) for 10 days. However, resochin treatment was applied for positive novel coronavirus nucleic acid of respiratory sputum specimen after 11 days of treatment.

\section{Results}

Epidemiology: In all selected four families, each family had 1-2 members who had contacted epidemic diseases.

Blood routine examination and changes in biochemical criteria: Patients 1-2 showed increases of leukocytes, NEUT and C-reactive protein. Patients 8-11 had 9-item respiratory test and mycoplasma was positive. Blood routine examination and changes in biochemical criteria are shown in Table.1.

Table 1 Blood routine examination and changes in biochemical parameters. 


\begin{tabular}{|c|c|c|c|c|c|c|c|c|c|c|c|}
\hline $\begin{array}{l}\text { Laboratory } \\
\text { examination }\end{array}$ & 1 & 2 & 3 & 4 & 5 & 6 & 7 & 8 & 9 & 10 & 11 \\
\hline $\begin{array}{l}\text { Leukocytes } \\
\left(10^{\wedge} 9 / \mathrm{L}\right)\end{array}$ & 9.7 & 7.9 & 7.9 & 8.5 & 4.8 & 3.8 & 3.4 & 6.6 & 9.5 & 4.9 & 4.8 \\
\hline $\begin{array}{l}\text { Lymphocyte } \\
\text { ratio } \% \square\end{array}$ & 9.6 & 13 & 22.7 & 25.3 & 27.9 & 22 & 24.3 & 38.1 & 13.7 & 37.4 & 28.6 \\
\hline NEUT $\square \% \square$ & 81 & 79.1 & 72 & 69.4 & 58.5 & 69.6 & 61.7 & 51.5 & 80.1 & 54 & 61.6 \\
\hline $\begin{array}{l}\text { C-reactive } \\
\text { protein } \llbracket \mathrm{mg} / \mathrm{L} \square\end{array}$ & 134.39 & $\begin{array}{l}153.35 \\
\uparrow\end{array}$ & $\begin{array}{l}17.93 \\
\uparrow\end{array}$ & 0.69 & 0.52 & 0.85 & 9.18 & $<0.499$ & $<0.499$ & $<0.499$ & $<0.499$ \\
\hline $\begin{array}{l}\text { Serum PCT } \\
\square \mathrm{ng} / \mathrm{ml} \square\end{array}$ & 0.09 & 0.47 & $<0.05$ & $<0.05$ & 0.06 & 0.05 & 0.05 & $<0.05$ & $<0.05$ & $<0.05$ & $<0.05$ \\
\hline $\mathrm{ESR} \rrbracket \mathrm{mm} / \mathrm{h} \square$ & $\begin{array}{l}100 \\
\uparrow\end{array}$ & $\begin{array}{l}97 \\
\uparrow\end{array}$ & $\begin{array}{l}55 \\
\uparrow\end{array}$ & $\begin{array}{l}43 \\
\uparrow\end{array}$ & $\begin{array}{l}55 \\
\uparrow\end{array}$ & - & $\begin{array}{l}25 \\
\uparrow\end{array}$ & 4 & 6 & 14 & $\begin{array}{l}45 \\
\uparrow\end{array}$ \\
\hline $\begin{array}{l}\text { Myohemoglobin } \\
\text { test\ng/ml }\end{array}$ & 57 & 60.5 & 21.4 & 24.5 & 143.8 & 63.7 & 31 & 30.1 & 43.8 & 24.1 & 4.8 \\
\hline $\begin{array}{l}\text { Troponin I test } \\
\square \mathrm{pg} / \mathrm{ml} \square\end{array}$ & 8.2 & 12.7 & 2.6 & 3.8 & 27.2 & 27 & 4.5 & 2.4 & 0.5 & 0.3 & 0.1 \\
\hline $\begin{array}{l}\text { Creatine kinase } \\
\text { isoenzyme } \\
\square \mathrm{ng} / \mathrm{ml} \square\end{array}$ & 0.5 & 0.8 & 0.5 & 1.5 & 2.6 & 0.9 & 0.5 & 1.9 & 0.5 & 0.4 & 0.3 \\
\hline $\begin{array}{l}\text { Alanine } \\
\text { aminotransferase } \\
\square \mathrm{U} / \mathrm{L} \square\end{array}$ & 19.7 & $\begin{array}{l}70.7 \\
\uparrow\end{array}$ & 17.9 & 21.1 & 15.5 & 7.2 & 37.2 & 20.1 & 11.7 & 34.7 & 32.8 \\
\hline $\begin{array}{l}\text { Aspartate } \\
\text { aminotransferase } \\
\square \mathrm{U} / \mathrm{L} \square\end{array}$ & 25.6 & $\begin{array}{l}105.7 \\
\uparrow\end{array}$ & 27 & 25.9 & 49.7 & 39.2 & $42.4 \uparrow$ & 36.1 & 20.1 & 28.5 & 27.2 \\
\hline TBiløumol/L】 & 8.5 & 12.1 & 6.6 & 4.9 & 8.7 & 19.7 & 5.6 & 4.2 & 5.4 & 14.9 & 16.3 \\
\hline $\begin{array}{l}\text { Direct bilirubin } \\
\text { \umol/L口 }\end{array}$ & 3.5 & 6.4 & 1.8 & 1.5 & 2 & 6.3 & 1.3 & 1 & 1.6 & 2.7 & 3.4 \\
\hline & & & & & & & & & & & \\
\hline
\end{tabular}




\begin{tabular}{|c|c|c|c|c|c|c|c|c|c|c|c|}
\hline $\begin{array}{l}\text { Indirect } \\
\text { bilirubin\umol/L } \square\end{array}$ & 5 & 5.7 & 4.8 & 3.4 & 6.7 & 13.4 & 4.3 & 3.2 & 3.8 & 12.2 & 12.9 \\
\hline $\begin{array}{l}\text { Creatinine } \\
\mathrm{mmol} / \mathrm{L}\end{array}$ & 6.3 & 6.3 & 3.7 & 4.3 & 6.2 & 4.2 & 2.8 & 5.3 & 2.6 & 4.6 & 4.2 \\
\hline $\begin{array}{l}\text { Urea nitrogen } \\
\text { umol/L }\end{array}$ & 73 & 69 & 42 & 55 & 75 & 77 & 55 & 34 & 68 & 79 & 51 \\
\hline D-dimer $\llbracket$ ug $/ \mathrm{ml} \square$ & 0.56 & $\begin{array}{l}1.39 \\
\uparrow\end{array}$ & 0.36 & 0.43 & 0.47 & 1.34 & 0.3 & 0.18 & 0.18 & 0.19 & 0.41 \\
\hline $\begin{array}{l}\text { Oxygen } \\
\text { saturation at } \\
\text { admission \% }\end{array}$ & 92 & 92 & 99 & 97 & 97 & 96 & 97 & 98 & 98 & 98 & 99 \\
\hline
\end{tabular}

Clinical manifestation: 3 cases had debilitation only, 1 case had cough only, 1 case had diarrhea (4 years old), 5 cases had fever and cough, and 1 case had blood-stained sputum.

Imaging manifestations: imaging changes of 11 patients: 1 case had no imaging change. Multiple focal GGOs were detected from 2 patients and multiple patchy shadows were observed from 8 patients, especially in lung periphery. Typical imaging manifestations are shown in Fig.1-2.

Combination of basic diseases: three cases had hypertension, 2 cases had diabetes and 1 case had hypertension and diabetes. Moreover, there's one patient who had rheumatic heart disease and received mitral and aortic valve replacement 2 years ago. There's another one who had depression and suicidal tendency. There were 1 mild patient, 8 moderate patients, 1 severe patient and 1 critical patient. The severe and critical patients had complications of diabetes.

Diagnosis method: 9 cases showed positive in novel coronavirus nucleic acid test and 2 cases showed positive in pharynx test of novel coronavirus nucleic acid.

Therapeutic effect: Lopinavir/ritonavior combined with ribavirin or $\mathrm{RHI} a 2 \mathrm{~b}$ was effective for 1 mild patient and 7 moderate patients. However, the Lopinavir/ritonavior combined with RHI a2b failed to relieve respiratory symptoms of severe and critical patients. Therefore, resochin treatment was applied, which achieved effective clinical outcome. One moderate patient remained positive in nucleic acid test of respiratory phlegm samples after lopinavir/ritonavior treatment, and resochin treatment was applied, which made nucleic acid turn to negative.

Adverse reaction: 4 patients had loose stools and abdominal discomfort, and another two patients had diarrhea. All patients developed evident liver and kidney disorders. 
Prognosis: All patients recovered normal body temperature, significantly relieved respiratory symptoms and digestive tract symptoms, significant coefficient of exudative lesion at lung according to chest CT and negative novel coronavirus nucleic acid of continuous two respiratory sputum specimens (sampling interval is at least 1 day) after the treatment. Follow-up visit was performed after 2 weeks of discharge, which discovered no discomfort.

Disisolation and discharge standards: All 11 patients met the discharge criteria and were discharged. Typical imaging performance is shown in Figure 3.

Follow-up visit: 11 patients were asked not to go for outdoor activities and return to hospital for follow-up visit and return visit at the second and fourth weeks after discharge. None of the 11 patients had discomfort, and CT images showed increased density of lamellar ground glass in the subpleural area of the lower lobe of both lungs has been completely absorbed and disappeared.

SARS-CoV-2 nucleic acid test was negative in sputum, blood and stool. Typical imaging performance is shown in Figure 4.

\section{Discussions}

In 1965, Tyml et al. separated a strain of virus from snot of patients with common old by human embryo trachea culture method and named it as B814 virus. Subsequently, Harare et al. separated similar virus through human embryo nephrocytes and the representative strain was named 229E virus. In 1967, Mclntosh separated a batch of virus from patients with cold through human embryo trachea culture method and its representative strain was OC43 strain. In 1968, Almeida et al. studied morphologies of these viruses and they found from electron microscope that these viruses have corona-like spinous processes on the diolame. Therefore, they suggested to naming this type of virus as coronavirus. In 1975, the National Virus Naming Committee proposed an official name of coronaviridae. Coronavirus is a kind of RNA virus which has extensive distributions in human and animals, and it belongs to Coronaviruses, Coronaviridae, Nidovirale. It can cause diseases of respiratory tract, digestive track, liver and nervous system. Severe acute respiratory syndrome coronavirus (SARS-CoV) and Middle East Respiratory Syndrome coronavirus (MERS-CoV) are known fetal $\beta$-type coronavirus [3, 4]. According to the complete genome sequencing of respiratory samples of patients with the novel coronavirus, it found that sequence of novel coronavirus matched with B pedigree of $\beta$-type coronavirus and it is similar with those of SARSCoV and MERS-CoV. However, the consistence of novel coronavirus with SARS-CoV and MERS-CoV in the conserved region replication (ORF lab) enzyme is lower than $90 \%$. International Committee on Taxonomy of Viruses (ICTV) named the novel coronavirus as SARS-CoV-2 according to systematology, taxonomy and conventions [5].

SARS-CoV-2 acts on ACE2 on human cell surface through the furcella S protein and the S protein drives integration of virus membrane and host cytomembrane through structural rearrangement, thus infecting respiratory epithelial cells of human. According to biophysics and structural evidences, the bonding strength between SARS-CoV-2 and ACE2 is about $15 \mathrm{nmol} / \mathrm{L}$, and SARS-CoV-2 has stronger affinity than 
SARS-CoV $[5,6]$, which determines its stronger infectivity. Besides, the single cell RNA sequencing data showed expressions of ACE2 in heart, kidney, liver, bladder and ileum [7, 8], indicating the risk of these organs from virus infection in addition to lung. In this study, respiratory symptoms are common in patients with SARS-CoV-2 infection and 6 patients of 11 have respiratory symptoms. There's one patient with digestive tract symptoms as the main symptom. Moreover, this study proves that the SARS-CoV- 2 is easy to be spread in a family.

Currently, infected patients are viewed as the source of SARS-CoV-2 and asymptomatic patients might carry the virus [9]. Short-distance respiratory spraying and direct or indirect contact are major spreading ways of SARS-CoV-2, such as mouth, nose and eye mucous membrane infection with hands. Aerosol transmission might occur in a relatively closed environment with relatively high virus concentration. However, there's no evidence to prove that aerosol transmission is a major spreading way [10]. In this investigation, we also found that all 11 patients came from 4 families and each family had 1-2 members who had contacted with SARS-CoV-2 infected patients. This reveals the possibility of direct or indirect contact transmission, thus infecting other family members. Therefore, the whole family in which there's a patient with confirmed SARS-CoV-2 shall be isolated for screening in addition to the patient. According to chest X-ray examination, the rate of missed diagnosis of patients who mainly present early lesion or GGO density is relatively high [11]. Chest CT examination is irreplaceable for recognition of pneumonia, which is mainly attributed to high-resolution CT [11]. In this investigation, imaging changes of 11 patients include multiple GGO in 2 cases, and multiple patchy shadows in 9 patients, especially in lung periphery. These conform to the latest report [11].

No specific medicine for SARS-CoV-2 has been developed yet [10]. Lopinavir/ritonavior is a kind of medicine for human immunodeficiency virus (HIV) infection. Lopinavir can inhibit a key "protease" in the replication process of HIV, but it is decomposed quickly by hepatic microsomal enzymes (mainly CYP3A) in vivo. Ritonavior is another protease inhibitor and it can inhibit hepatic microsomal enzyme CYP3A significantly, thus increasing the concentration of lopinavir in blood. Hence, lopinavir/ritonavior can strengthen resistance to HIV [12]. Studies have found that lopinavir can inhibit the major protease Mproo of SARS-CoV. During SARS epidemic in 2003, a scholar from Hong Kong, China found that lopinavir/ritonavior could lower the incidence and death rate of acute respiratory distress syndrome. When screening drugs to inhibit MERS-CoV from the drug database which is approved by FDA, it found that lopinavir could inhibit MERS-CoV activity by a low concentration [13]. Moreover, lopinavir/ritonavior could decrease death rate of lemur for MERS-CoV infection [13]. According to an in vitro study, lopinavir/ritonavior could resist virus by inhibiting replication of MERS-CoV and SARS-CoV $[14,15]$. Ribavirin is a kind of cynic analog and a type of broad spectrum antiviral drug. On the one hand, it is mainly used to treat respiratory syncytial virus (RSV) infection. On the other hand, it is mainly used to cooperate with interferon to treat hepatitis $C$ virus. During SARS in 2003 , ribavirin was applied to treat SARS-CoV infection, finding that ribavirin could lower fatality rate and proportion of trachea cannula significantly [16]. Almekhlafi et al. carried out a cohort study and pointed out that ribavirin can treat MERSCoV infection to some extent [17]. Therefore, 9 patients with SARS-CoV-2 infection in this study were treated by lopinavir/ritonavior combined with ribavirin, and all of them were cured. This proves that 
lopinavir/ritonavior combined with ribavirin might be effective for SARS-CoV-2 infection. However, this has to be further proved by expanding samples and a multicenter control study. Besides, it claims a mild side effect and only few patients suffered adverse reactions like diarrhea, nausea, emesis, etc.

As a kind of broad spectrum antiviral drug, interferon (IFN) has not antiviral activity, but it can increase expression of the major histocompatibility complex (MHC) I, increase representation of viral antigens on infected cell surface, and promote recognition of immune system of the body to virus infected cells [18]. According to an in vitro study, IFN and ribavirin were added into the kidney cell lines of rhesus infected by MERS-CoV. It found that the combined use of IFN and ribavirin can inhibit growth of MERS-CoV more effectively than the independent use of ribavirin. Besides, the in vivo study of rhesus animal model also proved the prognosis improvement of combination of IFN and ribavirin [7, 8]. Loutfy et al. [9] compared clinical effects of IFN a combined with glucocorticoid and independent use of glucocorticoid in treatment of SARS-CoV infection. They pointed out that the IFN a combined with glucocorticoid could shorten relieving time of lung image by $50 \%(P=0.001)$ and improve oxygen saturation significantly $(P=0.02)$. Therefore, some patients were treated by aerosol inhalation of IFN.

Chloroquine has been applied in clinics for over 70 years because of its economic efficiency and safety. Recently, it is reported that chloroquine has potential broad spectrum antiviral activity. Chloroquine can increase $\mathrm{pH}$ in lysosome, thus hindering integration of virus and cells and thereby blocking virus infection in human cells [18]. Moreover, some study pointed that that chloroquine can interfere glycosylation of SARS-CoV cell receptor, thus developing the antiviral effect [19]. After the occurrence of 2019-nCoV infection epidemic, Wuhan Institute of Virology carried out an in vitro experimental study to explore the effective drug to resist 2019-nCoV. It found that chloroquine can continue to develop the antiviral effect after human cell infection by 2019-nCoV except for above two antiviral mechanisms. Chloroquine also has immunoregulatory activity to strengthen antiviral effect.

\section{Conclusion}

Therefore, the novel coronavirus pneumonia is easy to be spread in a family and the infected member might cause other members in the family infected through direct or indirect contacts. For this reason, it is necessary to not only isolate and treat the people with SARS-CoV-2 infection, but also isolate other family members for screening. People with SARS-CoV-2 infection have complicated and diversified symptoms. Family members with a member confirmed SARS-CoV-2 infection shall be screened in time even though no symptoms have been developed yet. People with SARS-CoV-2 infection shall be administrated by lopinavir/ritonavior combined ribavirin and aerosol inhalation of IFN a as soon as possible. Moreover, chloroquine shall be applied if the above treatment seems to be invalid. Antibiotic therapy shall be adopted if necessary.

\section{Abbreviations}


SARS-CoV: Severe acute respiratory syndrome coronavirus; IFN :interferon; MERS-CoV: Middle East Respiratory Syndrome coronavirus; HIV: human immunodeficiency virus; ACE: Angiotensin-converting enzyme CRP : C-reactive protein; ESR: erythrocyte sedimentation rate; PCT: procalcitonin ; PaO2: Arterial partial pressure of oxygen; FiO2: oxygen uptake

\section{Declarations}

\section{Ethics approval and consent to participate}

It was approved by the Sichuan West China Hospital Hospital and Sichuan University Research Ethics Boards. The trial was registered in the Chinese Clinical Trials Registry (ChiCTR-IOR-17008507). Written informed consent for participation in the study was obtained from parent or relative for participants. Written informed consent was obtained from a parent for participants under 16 years old.

\section{Patient consent for publication}

Not applicable

\section{Availability of data and materials}

The datasets used and/or analyzed in the study are available from the corresponding author on reasonable request.

\section{Competing interests}

The authors declare that they have no competing interests.

\section{Funding}

Not applicable.

\section{Author Contributions}

$R Q, M W L, W M L$ and $C Z$ made contributions to the acquisition and analysis of data. WML and $C Z$ contributed to the interpretation of data. RQ and MWL designed the study and drafted the manuscript. All authors have read and given final approval for the version submitted for publication.

\section{Acknowledgments}

The authors are grateful for the excellent technical assistance provided by medical and nursing staff in our hospital infection department.

\section{References}


1 Russel CD, Millar JE, Baillie JK. Clinical evidence does not support corticosteroid treatment for SARSCoV-2 lung injury. The Lancet, 2020. DOI:10.1016/S0140-6736(20)30317-2.

2 World Health Organization: Clinical management of severe acute respiratory infection when Novel coronavirus (nCoV) infection is suspected: interim Guidance [EB/OL]区2020-01-28区[2020-02-05]

3 Tan YJ , Lim SG , Hong W. Understanding the accessory viral proteins unique to the severe acute respiratory syndrome ( SARS ) coronavirus [ J ] .Antiviral Res , 2006,72 ( 2 ): 78-88

4 Jo S , Kim H, Kim S, Shin DH, Kim MS . Characteristics of flavonoids as potent MERS-CoV 3C-like protease inhibitors. Chem Biol Drug Des 2019 Dec;94 (6): 2023-2030

5 Liu Z, Xiao X, Wei X, Li J, Yang J, Tan H, Zhu J, Zhang Q, Wu J, Liu L. Composition and divergence of coronavirus spike proteins and host ACE2 receptors predict potential intermediate hosts of SARS-CoV-2. J Med Virol. 2020 Feb 26. doi: 10.1002/jmv.25726.

6 Xia J, Tong J, Liu M, Shen Y, Guo D. Evaluation of coronavirus in tears and conjunctival secretions of patients with SARS-CoV-2infection. J Med Virol. 2020 Feb 26. doi: 10.1002/jmv.25725.

7 Xu J, Zhao S, Teng T, Abdalla AE, Zhu W, Xie L, Wang Y, Guo X. Systematic Comparison of Two Animalto-Human Transmitted Human Coronaviruses: SARS-CoV-2and SARS-CoV.Viruses. 2020 Feb 22;12(2). pii: E244. doi: 10.3390/v12020244.

8 Letko M, Marzi A, Munster V. Functional assessment of cell entry and receptor usage for SARS-CoV2 and other lineage B betacoronaviruses. Nat Microbiol. 2020 Feb 24. doi: 10.1038/s41564-020-0688-y.

9 Xu K, Cai H, Shen Y, Ni Q, Chen Y, Hu S, Li J, Wang H, Yu L, Huang H, Qiu Y, Wei G, Fang Q, Zhou J, Sheng J, Liang T, Li L. [Management of coronavirus disease-19 (COVID-19): the Zhejiang experience]. Zhejiang Da Xue Xue Bao Yi Xue Ban. 2020 Feb 21;49(1):0. Chinese.

10 Tong ZD, Tang A, Li KF, Li P, Wang HL, Yi JP, Zhang YL, Yan JB. Potential Presymptomatic Transmission of SARS-CoV-2, Zhejiang Province, China, 2020. Emerg Infect Dis. 2020 May 17;26(5). doi: 10.3201/eid2605.200198. [Epub ahead of print]

11 Qin C, Liu F, Yen TC, Lan X. F-FDG PET/CT findings of COVID-19: a series of four highly suspected cases. Eur J Nucl Med Mol Imaging. 2020 Feb 22. doi: 10.1007/s00259-020-04734-w. [Epub ahead of print]

12 Su B, Wang Y, Zhou R, Jiang T, Zhang H, Li Z, Liu A, Shao Y, Hua W, Zhang T, Wu H, He S, Dai L, Sun L. Efficacy and Tolerability of Lopinavir/Ritonavir- and Efavirenz-Based Initial Antiretroviral Therapy in HIV-1Infected Patients in a Tertiary Care Hospital in Beijing, China. Front Pharmacol. 2019 Dec 12;10:1472.

$13 \mathrm{Wu} \mathrm{CY}$, Jan JT, Ma SH, et al. Small molecules targeting severe acute respuatory Syndrome human coronavirus [ J]. Proc Naù Acad Sci U S A , 2004,101 (27) : 10012-10017 
14 Hung KKC, Mark CKM, Yeung MPS, Chan EYY, Graham CA. The role of the hotel industry in the response to emerging epidemics: a case study of SARS in 2003 and H1N1 swine flu in 2009 in Hong Kong.Global Health. 2018 , 14(1):117.

15 Chan JF, Yao Y, Yeung ML, Deng W, Bao L, Jia L, Li F, Xiao C, Gao H, Yu P, Cai JP, Chu H, Zhou J, Chen H, Qin C, Yuen KY. Treatment With Lopinavir/Ritonavir or Interferon- $\beta 1 \mathrm{~b}$ Improves Outcome of MERS-CoV Infection in a Nonhuman Primate Model of Common Marmoset. J Infect Dis. 2015,212(12):1904-13.

16 de Wilde AH, Falzarano D, Zevenhoven-Dobbe JC, Beugeling C, Fett C, Martellaro C, Posthuma CC, Feldmann H, Perlman S, Snijder EJ.Alisporivir inhibits MERS- and SARS-coronavirus replication in cell culture, but not SARS-coronavirus infection in a mouse model.Virus Res. 2017, 228:7-13

17 Falzarano D, de Wit E, Rasmussen AL, Feldmann F, Okumura A, Scott DP, Brining D, Bushmaker T, Martellaro C, Baseler L, Benecke AG, Katze MG, Munster VJ, Feldmann H. Treatment with interferon-a2b and ribavirin improves outcome in MERS-CoV-infected rhesus macaques.Nat Med. 2013, 19(10):1313-7.

18 Channappanavar R , Fehr AR , Zheng J , Wohlford-Lenane C , Abrahante JE , Mack M , Sompallae $\mathrm{R}, \mathrm{McC}$ ray PB , Meyerholz DK, Perlman S. IFN-I response timing relative to virus replication determines MERS coronavirus infection outcomes. J Clin Invest 2019, 130 3625-3639.

19 Falzarano D , de Wit E, Rasmussen AL , Feldmann F , Okumura A, Scott DP , Brining D , Bushmaker $T$, Martellaro C, Baseler L , Benecke AG , Katze MG ,Munster VJ , Feldmann H. Treatment with interferona2b and ribavirin improves outcome in MERS-CoV-infected rhesus macaques. Nat Med 2013 Oct;19 (10): 1313-7

20 Momattin H, Mohammed K, Zumla A, Memish ZA, Al-Tawfiq JA. Therapeutic options for Middle East respiratory s yndrome coronavirus

(MERS-CoV)--possible lessons from a systematic review of SARS-CoV therapy. Int J Infect Dis. 2013. 17(10): e792 -8.

21Loutfy MR, Blatt LM, Siminovitch KA, Ward S, Wolff B, Lho H, Pham DH ; Hassan, Deif H, LaMere EA, Chang M, Kain KC, Farcas GA, Ferguson P, Latchford M, Levy G, Dennis JW, Lai EY, Fish EN. Interferon alfacon-1 plus corticosteroids in severe acute respiratory s yndrome: a preliminary study. JAMA. 2003. 290(24): 3222-8.

22 Kaur S, Prasad N, Srivastava A, Kumari M, Singh S, Kumar D, Bhattacharyya R, Banerjee D. Fluorescence spectra of chloroquine suspension: A probable tool for quality assessment of the most common antimalarial in a user-friendly manner.Indian J Pharmacol. 2019,51(6):416-417.

23 de Wilde AH, Jochmans D, Posthuma CC, Zevenhoven-Dobbe JC, van Nieuwkoop S, Bestebroer TM, van den Hoogen BG, Neyts J, Snijder EJ. Screening of an FDA-approved compound library identifies four 
small-molecule inhibitors of Middle East respiratory syndrome coronavirus replication in cell culture. Antimicrob Agents Chemother. 2014, 58(8):4875-84.

24 Colson P, Rolain JM, Raoult D. Chloroquine for the 2019 novel coronavirus SARS-CoV-2. Int J Antimicrob Agents. 2020 Feb 15:105923. doi: 10.1016/j.ijantimicag.2020.105923.

\section{Figures}
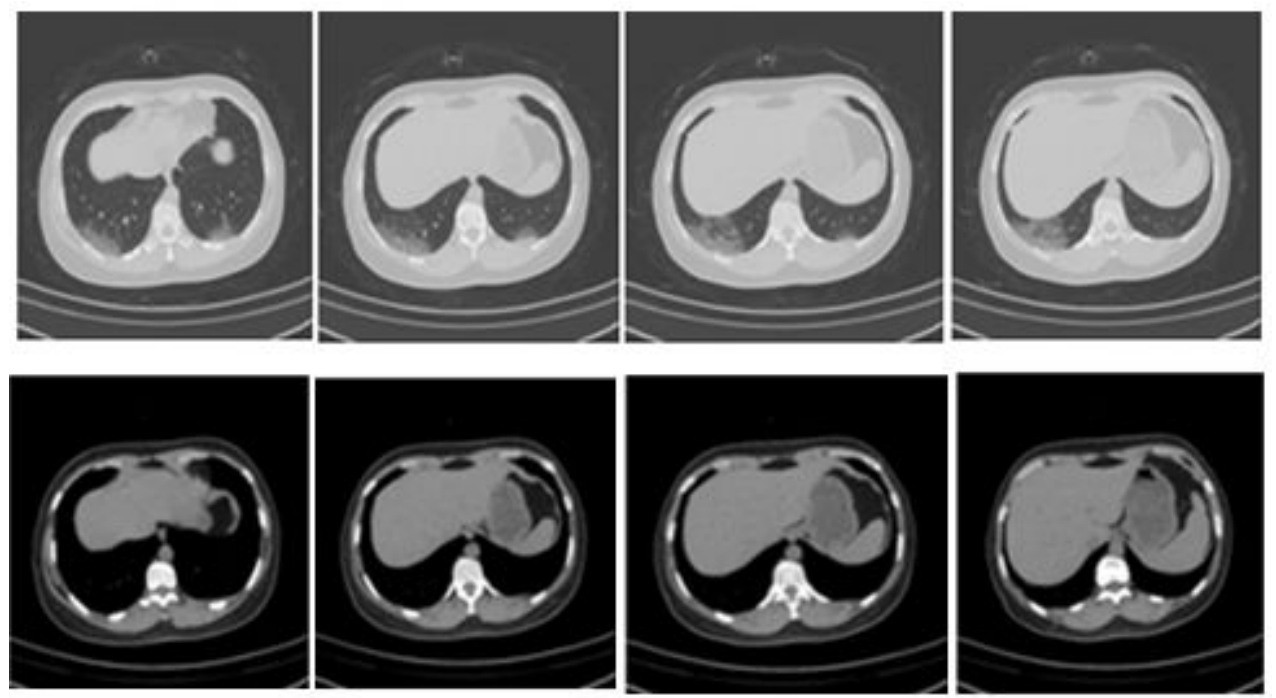

Figure 1

Typical imaging manifestations before the treatment. CT images showed increased density of lamella ground glass in the subpleural area of the lower lobe of both lungs.
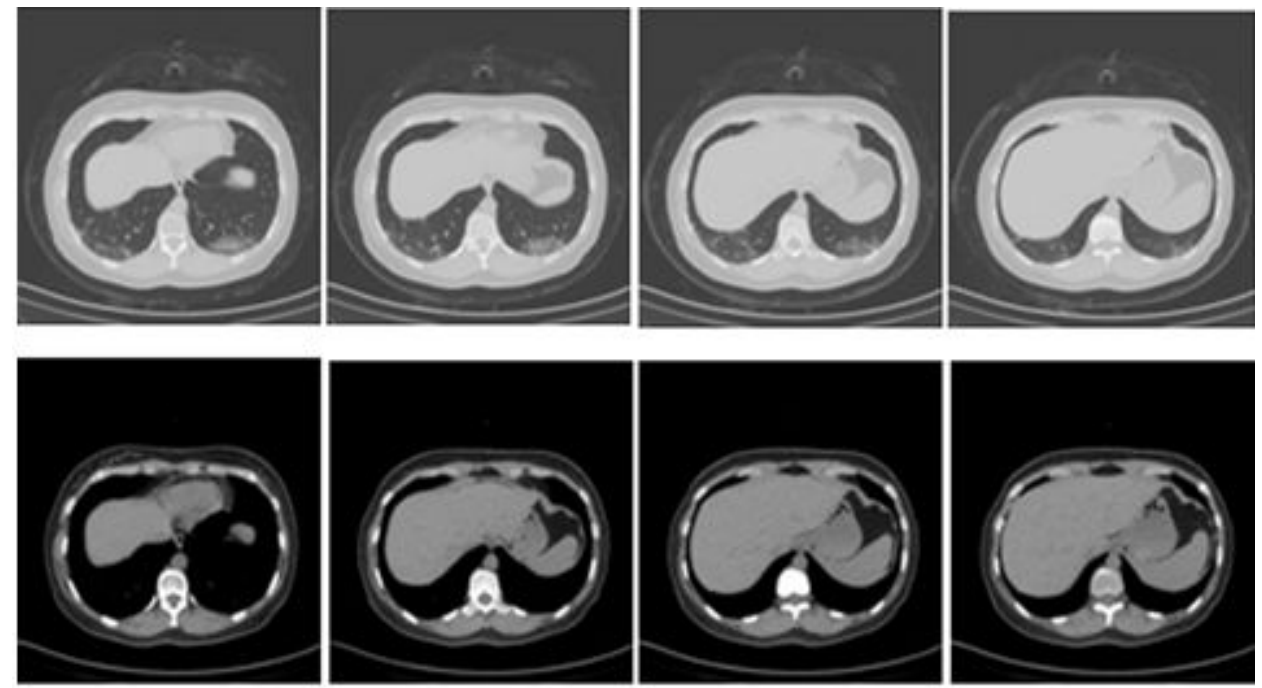

\section{Figure 2}

Typical imaging manifestations during the treatment. CT images showed increasing density of lamellar ground glass in the lower pleura area of the lower lungs, thickening of local lobular septum, thickening of 
the pleura, compared with before treatment, the lower lobe lesions in the right lung were reduced and the scope was broadened and the left lower lobe lesions were increased.
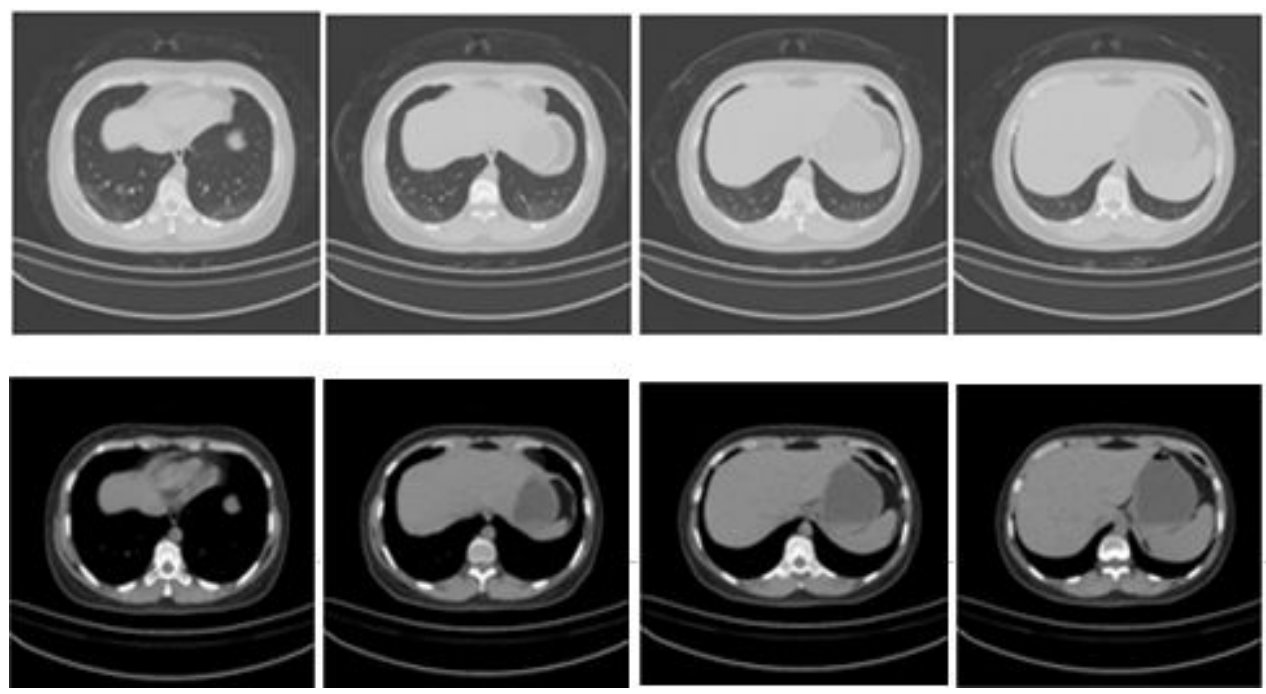

\section{Figure 3}

Typical imaging manifestations after treatment. CT images showed increasing the density of lamellar ground glass in the lower pleura, area of the lower lobe of the two lungs, thickening of the local lobular septum, and thickening of the adjacent pleura. Compared with before and during treatment, the scope of the lower lobe lesions in the two lungs is reduced and the density is reduced.
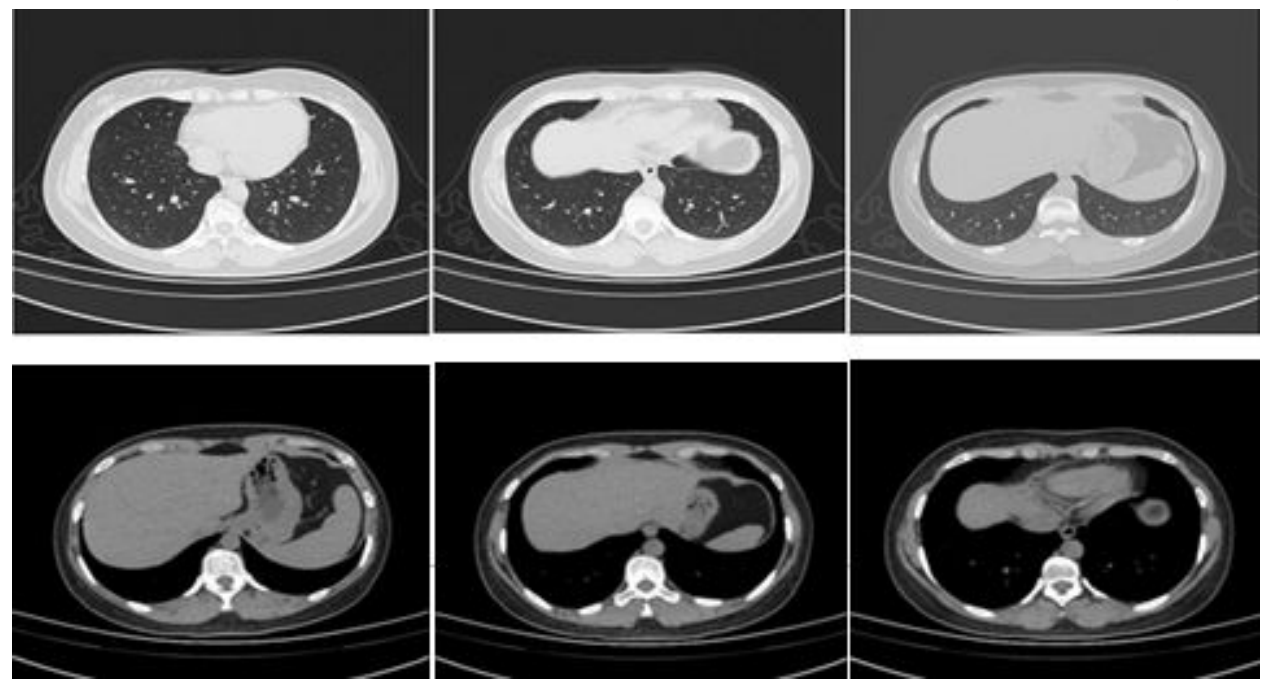

\section{Figure 4}

Typical imaging manifestations in follow-up visit after 2 weeks of discharge. CT images showed increased density of lamellar ground glass in the subpleural area of the lower lobe of both lungs has been completely absorbed and disappeared 